\title{
COST BASED TASK SCHEDULING ALGORITHM IN CLOUD COMPUTING
}

\author{
Shikha Garg ${ }^{1}$, Kapil Govil ${ }^{2}$, Brijmohan $\operatorname{Singh}^{3}$ \\ ${ }^{1}$ Lecturer, CCSIT, TMU, Moradabad (U.P.), India \\ ${ }^{2}$ Assistant Professor, CCSIT, TMU, Moradabad (U.P.), India \\ ${ }^{3}$ Associate Professor, College of Engineering Roorkee, Roorkee (Uttarakhand), India
}

\begin{abstract}
Cloud computing provides various significant services to the user including software as service, Infrastructure as a service. User submits the tasks to acquire various services provided by Cloud. In Cloud computing environment these task are scheduled. There are two levels of scheduling which is done in Cloud Computing. One is called platform level where task from different users are scheduled on Virtual Machines for proper execution, another one is called infrastructure level where different virtual machines are scheduled on physical machines provided in Data Centres. This paper elaborates an efficient cost based task scheduling algorithm. The problem of processing " $m$ " jobs to " $n$ " virtual machines in Cloud Computing is addressed here where number of task is greater than the number of service provider. As day by day numbers of user are increasing, problem of efficiently allocation of different jobs has become a great issue. This algorithm efficiently allocates different tasks to increase the performance of Cloud computing.
\end{abstract}

Keywords-Allocation, Cloud computing, Efficiency, Scheduling, Service Provider

****.

\section{INTRODUCTION}

Cloud Computing is an emerging technology in today era. It provides a virtual view of resources to the user that is available by the service provider [1]. Elaboration of basic concept of Cloud Computing is given in [2-4]. Service provider gives the opportunity to the user to attain the services from the Cloud. It allocates the infrastructure, software and platform as a service to the different jobs submitted by the user. This helps the user to scale up the revenue from business.

Task scheduling algorithms provides a way to assign various tasks on different virtual machines. Hong Sun et. al.[5] explains about the features of task scheduling specially global centralization, scalability, dynamically self adaptive. They have also given detail of targets of task scheduling including Quality of Service (QoS), load balancing, best running time and increment in throughput of the system. An efficient scheduling algorithm is required to achieve all the targets of algorithm. The classification of resource allocation and scheduling schemes is elaborated in [7]. In Cloud computing as resources are minimum so the aim of task scheduling algorithm is to minimize the make span of tasks [6].

This paper explains an efficient task scheduling algorithm that assign different task to different virtual machines.

\section{OBJECTIVE}

The objective of the present research paper is to enhance the performance of the Cloud computing and achieve better throughput in less time by using the proper utilization of its virtual machines (VM) residing on data centres and as well as proper allocation of tasks on them. The type of allocation of task to VM is static. As in this paper the performance is measured in terms of cost, so we have to minimize the cost to obtain the best performance from Cloud computing.

\section{TECHNIQUE}

In order to evaluate the overall optimal processing cost on $\mathrm{VM}$ in Cloud computing, the problem is selected where a set $\mathrm{VM}=\left\{\mathrm{v}_{1}, \mathrm{v}_{2}, \mathrm{v}_{3}, \ldots \ldots \mathrm{v}_{\mathrm{n}}\right\}$ of ' $\mathrm{n}$ ' virtual machines and a set $\mathrm{T}$ $=\left\{\mathrm{t}_{1}, \mathrm{t}_{2}, \mathrm{t}_{3}, \ldots . . \mathrm{t}_{\mathrm{m}}\right\}$ of ' $\mathrm{m}$ ' tasks, where $\mathrm{m}$ is greater than $\mathrm{n}$. The processing cost of each task to each and every VM is known and it is mentioned in the Processing Cost Matrix of order $\mathrm{m} \mathrm{x} \mathrm{n}$. For each task, the overall load on each processor is evaluated; and the task on the processor is allocated. Task is selected on the basis of minimum processing load by using Shortest Job First (SJF) algorithm as it helps in providing maximum throughput. Finally the addition of total processing cost of task is done, which are assigned to specified VM to obtain optimal results.

\section{ALGORITHM}

Step 1: Start Algo

Step 2: Read the number of VM in $n$

Step 3: do

Step 4: $\quad$ \{

Step 5: $\quad$ If task is available

Step 6: Read the processing cost with each VM (n) in processor cost matrix (PCM)

Step 7: $\quad$ End if

Step 8: $\quad$ Count the number of tasks in $m$

Step 9: \} while (task is available) 
Step 10: For $\mathrm{I}=1$ to $\mathrm{n}$

Step 11: Assign $\mathrm{n}$ task to $\mathrm{n}$ VM for which processing cost is minimum in Shortest Job First (SJF) order

Step 12: $\mathbf{J}=\mathrm{I}+1$

Step 13: End for

Step 14: $\mathrm{k}=\mathrm{m}-\mathrm{n}$

Step 15: For $\mathrm{I}=\mathrm{k}$ to $\mathrm{m}$

Step 16: for task I:

Step 17: Evaluate the overall load on each VM

Step 18: Allocate the task I on VM, which have the minimum load

Step 19: If load are equal for more than $1 \mathrm{VM}$

Step 20: $\quad$ Assign the task for the VM less number of the already assigned task (s).

Step 21: Assign task which have smallest processing cost Step 22: $\quad$ End if

Step 23: $\quad \mathrm{I}=\mathrm{I}+1$

Step 24: End For

Step 26: Compute total processing cost by adding total processing cost of task, which are assigned at specified VM

Step 27: End Algorithm

\section{IMPLEMENTATION}

In order to evaluate the overall optimal processing cost of virtual machines in Cloud computing, the problem where a set $\mathrm{VM}$ of 4 virtual machines $\{\mathrm{v} 1, \mathrm{v} 2, \mathrm{v} 3, \mathrm{v} 4\}$ and a set $\mathrm{T}$ of 10 tasks $\{\mathrm{t} 1, \mathrm{t} 2, \mathrm{t} 3, \mathrm{t} 4, \mathrm{t} 5, \mathrm{t} 6, \mathrm{t} 7, \mathrm{t} 8, \mathrm{t} 9, \mathrm{t} 10\}$. It is shown in figure 1. The processing cost (c) of each task to each and every VM is known and it is mentioned in the Processor Cost Matrix PCM( , ) of order 4 x 10.

\begin{tabular}{|l|l|l|l|l|l|l|l|l|l|l|l|}
\hline \multirow{3}{*}{$\begin{array}{l}\operatorname{PCM}(,) \\
=\end{array}$} & & $\mathrm{t}_{1}$ & $\mathrm{t}_{2}$ & $\mathrm{t}_{3}$ & $\mathrm{t}_{4}$ & $\mathrm{t}_{5}$ & $\mathrm{t}_{6}$ & $\mathrm{t}_{7}$ & $\mathrm{t}_{8}$ & $\mathrm{t}_{9}$ & $\mathrm{t}_{10}$ \\
\cline { 2 - 12 } & $\mathrm{v}_{1}$ & 6 & 5 & 8 & 1 & 4 & 2 & 2 & 6 & 4 & 3 \\
\cline { 2 - 11 } & $\mathrm{v}_{2}$ & 2 & 3 & 7 & 4 & 5 & 1 & 8 & 7 & 5 & 7 \\
\cline { 2 - 11 } & $\mathrm{v}_{3}$ & 9 & 2 & 3 & 6 & 6 & 8 & 6 & 8 & 6 & 4 \\
\cline { 2 - 11 } & $\mathrm{v}_{4}$ & 3 & 1 & 4 & 3 & 2 & 9 & 7 & 9 & 2 & 2 \\
\hline
\end{tabular}

Now, first four tasks (i.e. $t_{1}, t_{2}, t_{3}, t_{4}$ ) to make $4 \times 4$ order matrix and on applying the algorithm of Assignment Problem [8] as given in the table 1 .

Table1: Task Allocation Table

\begin{tabular}{|l|l|}
\hline $\begin{array}{l}\text { Virtual } \\
\text { Machine }\end{array}$ & Task \\
\hline $\mathrm{v}_{1}$ & $\mathrm{t}_{4}$ \\
\hline $\mathrm{v}_{2}$ & $\mathrm{t}_{1}$ \\
\hline $\mathrm{v}_{3}$ & $\mathrm{t}_{3}$ \\
\hline $\mathrm{v}_{4}$ & $\mathrm{t}_{2}$ \\
\hline
\end{tabular}

Now, we have to select the VM which has the minimal processing load by adding the processing cost of next task (i. e. $\mathrm{t}_{5}$ ). On selecting $\mathrm{VM} \mathrm{v}_{4}$ as it has the minimal processing load, the following allocation is found as given in table 2 .

Table2: Task Allocation Table

\begin{tabular}{|l|l|}
\hline $\begin{array}{l}\text { Virtual } \\
\text { Machine }\end{array}$ & Task \\
\hline $\mathrm{v}_{1}$ & $\mathrm{t}_{4}$ \\
\hline $\mathrm{v}_{2}$ & $\mathrm{t}_{1}$ \\
\hline
\end{tabular}

\begin{tabular}{|l|l|}
\hline $\mathrm{v}_{3}$ & $\mathrm{t}_{3}$ \\
\hline $\mathrm{v}_{4}$ & $\mathrm{t}_{2} * \mathrm{t}_{5}$ \\
\hline
\end{tabular}

Again, the virtual machine which has the minimal processing load has to be selected by adding the processing cost of next task (i. e. $\mathrm{t}_{6}$ ). There are two $\mathrm{VM} \mathrm{v}_{1}, \mathrm{v}_{2}$ which have the same load (i.e. 3) so the virtual machine $v_{1}$ is selected can perform any task from same load which have highest priority by using Shortest Job First (SJF) [9] Policy. The task allocations are given in table 3 .

Table3: Task Allocation Table

\begin{tabular}{|l|l|}
\hline $\begin{array}{l}\text { Virtual } \\
\text { Machine }\end{array}$ & Task \\
\hline $\mathrm{v}_{1}$ & $\mathrm{t}_{4} * \mathrm{t}_{6}$ \\
\hline $\mathrm{v}_{2}$ & $\mathrm{t}_{1}$ \\
\hline $\mathrm{v}_{3}$ & $\mathrm{t}_{3}$ \\
\hline $\mathrm{v}_{4}$ & $\mathrm{t}_{2} * \mathrm{t}_{5}$ \\
\hline
\end{tabular}

By repeating the same algorithm, the VM has selected which has the minimal processing load by adding the processing cost of next task (i. e. $\mathrm{t}_{7}$ ). On selecting $\mathrm{VM} \mathrm{v}_{1}$ as it has the minimal processing load, the following allocation is presented as given in table 4 .

Table4: Task Allocation Table

\begin{tabular}{|l|l|}
\hline $\begin{array}{l}\text { Virtual } \\
\text { Machine }\end{array}$ & Task \\
\hline $\mathrm{v}_{1}$ & $\mathrm{t}_{4} * \mathrm{t}_{6} * \mathrm{t}_{7}$ \\
\hline $\mathrm{v}_{2}$ & $\mathrm{t}_{1}$ \\
\hline $\mathrm{v}_{3}$ & $\mathrm{t}_{3}$ \\
\hline $\mathrm{v}_{4}$ & $\mathrm{t}_{2} * \mathrm{t}_{5}$ \\
\hline
\end{tabular}

Now again, the virtual machine is selected which has the minimal processing load by adding the processing cost of next task (i. e. $\mathrm{t}_{8}$ ). On selecting $\mathrm{VM}_{4}$ as it has the minimal processing load, the following allocation is presented as given in table 5 .

Table5: Task Allocation Table

\begin{tabular}{|l|l|}
\hline $\begin{array}{l}\text { Virtual } \\
\text { Machine }\end{array}$ & Task \\
\hline $\mathrm{v}_{1}$ & $\mathrm{t}_{4} * \mathrm{t}_{6} * \mathrm{t}_{7}$ \\
\hline $\mathrm{v}_{2}$ & $\mathrm{t}_{1}$ \\
\hline $\mathrm{v}_{3}$ & $\mathrm{t}_{3}$ \\
\hline $\mathrm{v}_{4}$ & $\mathrm{t}_{2} * \mathrm{t}_{5} * \mathrm{t}_{8}$ \\
\hline
\end{tabular}

By repeating the same algorithm, the VMs are selected which have the minimal processing load by adding the processing cost of next task (i. e. $t_{9}$ ). On selecting $V M v_{2}$ as it has the minimal processing load, the following allocation is presented as given in table 6.

Table6: Task Allocation Table

\begin{tabular}{|l|l|}
\hline $\begin{array}{l}\text { Virtual } \\
\text { Machine }\end{array}$ & Task \\
\hline $\mathrm{v}_{1}$ & $\mathrm{t}_{4} * \mathrm{t}_{6} * \mathrm{t}_{7}$ \\
\hline $\mathrm{v}_{2}$ & $\mathrm{t}_{1} * \mathrm{t}_{9}$ \\
\hline $\mathrm{v}_{3}$ & $\mathrm{t}_{3}$ \\
\hline
\end{tabular}




\begin{tabular}{|l|l|}
\hline $\mathrm{v}_{4}$ & $\mathrm{t}_{2} * \mathrm{t}_{5} * \mathrm{t}_{8}$ \\
\hline
\end{tabular}

Again, the VMs are selected which have the minimal processing load by adding the processing cost of next task (i. e. $\mathrm{t}_{10}$ ). There are two VMs $\mathrm{v}_{3}, \mathrm{v}_{4}$ which have the same load (i.e. 7) so $v_{3}$ is selected by using Shortest Job First (SJF) [9] Policy. The task allocations are given in table 7.

Table7: Task Allocation Table

\begin{tabular}{|l|l|}
\hline $\begin{array}{l}\text { Virtual } \\
\text { Machine }\end{array}$ & Task \\
\hline $\mathrm{v}_{1}$ & $\mathrm{t}_{4} * \mathrm{t}_{6} * \mathrm{t}_{7}$ \\
\hline $\mathrm{v}_{2}$ & $\mathrm{t}_{1} * \mathrm{t}_{9}$ \\
\hline $\mathrm{v}_{3}$ & $\mathrm{t}_{3} * \mathrm{t}_{10}$ \\
\hline $\mathrm{v}_{4}$ & $\mathrm{t}_{2} * \mathrm{t}_{5} * \mathrm{t}_{8}$ \\
\hline
\end{tabular}

\section{CONCLUSION AND FUTURE SCOPE}

Task Scheduling has been a problematic issue in Cloud computing as the Cloud computing should provide better performance when multiple task are submitted to the cloud. This proposed algorithm allocates different virtual machine to the task based on processing cost and tasks are selected according to shortest job first manner. SJF provide the facility for better throughput from cloud computing. In future, a better scheduling algorithm can be developed that can enhance the performance of Cloud computing. In this, performance is measured in terms of processing cost of task that has been processed by the VMs and also these tasks have been processed optimally. The overall VM wise task allocation along with overall processing cost is given in table 8.

Table 8: Optimal Results

\begin{tabular}{|c|c|c|}
\hline $\begin{array}{l}\text { Virtual } \\
\text { Machine }\end{array}$ & Task & Processing Cost \\
\hline $\mathrm{v}_{1}$ & $\mathrm{t}_{4} * \mathrm{t}_{6} * \mathrm{t}_{7}$ & \multirow{4}{*}{31} \\
\hline $\mathrm{v}_{2}$ & $\mathrm{t}_{1} * \mathrm{t}_{9}$ & \\
\hline $\mathrm{v}_{3}$ & $\mathrm{t}_{3} * \mathrm{t}_{10}$ & \\
\hline $\mathrm{V}_{4}$ & $\mathrm{t}_{2} * \mathrm{t}_{5} * \mathrm{t}_{8}$ & \\
\hline
\end{tabular}

The VM wise processing cost graph is shown in the Fig. 1.

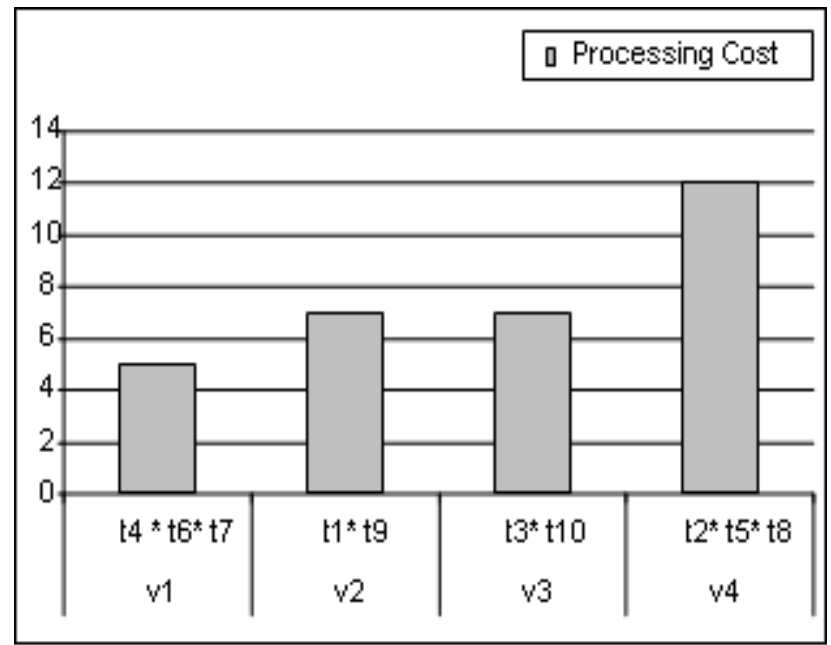

Fig. 1 VM wise processing cost graph

\section{REFERENCES}

[1] Yogita Chawla, Manshi Bhonsle, "Dynamically optimized cost based task scheduling in Cloud Computing," International of Emerging Trend \& Technology(IJETTCS), vol. 2, pp. 38-42, Issue 3, May-June 2013.

[2] Sohan Singh Yadav and ZengWen Hua, ": A Computing Infrastructure on Demand," IEEE, 2010.

[3] M. Malathi, "Cloud Computing Concept," IEEE, 2010.

[4] Peeyush Matrhur and Nikhil Nishchal, "Cloud Computing: New challenge to the entire computer industry," IEEE, 2010.

[5] Hong Sun, Shi-ping Chen, Chen Jin, Kai Guo, "Research and Simulation of Task Scheduling Algorithm in Cloud Computing," TELKOMNIKA, VOL. 11, No. 11, pp. 6664-6672, November, 2013.

[6] Vijayalakshmi A. Lepakshi, Dr. Prashanth C S R, "Astudy on Task Scheduling Algorithms in Cloud Computing," International Journal of Engineering and Innovative Technology (IJEIT), vol. 2, Issue 11, May 2013.

[7] Ms. Shubhangi D. Patil, Dr. S. C. Mehrotra, "Resource Allocation and Scheduling in the Cloud," International Journal of Emerging Trends and Technology in Computer Science, Vol. 1, Issue 1, May-June 2012.

[8] Kant Swaroop, P. K. Gupta and Man Mohan, Operations Research, Sultan Chand \& Sons, ISBN No.: 8180540200, 2002.

[9] Rajveer Kaur, Supriya Kinger,"Analysis of Job Scheduling Algorithms in Cloud Computing," International Journal of Computer Trends and Technology (IJCTT),Vol. 9, no. 7,pp. 379-386, Mar 2014. 